\title{
CC-PLA2-1 and CC-PLA2-2, two Cerastes cerastes venom-derived phospholipases $A 2$, inhibit angiogenesis both in vitro and in vivo
}

\author{
Raoudha Kessentini-Zouari ${ }^{1}$, Jed Jebali ${ }^{1}$, Salma Taboubi ${ }^{2}$, Najet Srairi-Abid ${ }^{1}$, Maram Morjen ${ }^{1}$, Olfa Kallech-Ziri ${ }^{1}$, \\ Sofiane Bezzine ${ }^{3}$, Jacques Marvaldi ${ }^{2}$, Mohamed El Ayeb ${ }^{1}$, Naziha Marrakchi ${ }^{1,4}$ and José Luis ${ }^{2}$
}

Integrins are essential in the complex multistep process of angiogenesis and are thus attractive targets for the development of antiangiogenic therapies. Integrins are antagonized by disintegrins and C-type lectin-like proteins, two protein families from snake venom. Here, we report that CC-PLA2-1 and CC-PLA2-2, two novel secreted phospholipases $\mathrm{A}_{2}\left(\mathrm{PLA}_{2}\right)$ isolated from Cerastes cerastes venom, also showed anti-integrin activity. Indeed, both $P L A_{2} s$ efficiently inhibited human brain microvascular endothelial cell adhesion and migration to fibrinogen and fibronectin in a dose-dependent manner. Interestingly, we show that this anti-adhesive effect was mediated by $\alpha 5 \beta 1$ and $\alpha \mathrm{v}$-containing integrins.

CC-PLA2s also impaired in vitro human brain microvascular endothelial cell tubulogenesis on Matrigel and showed

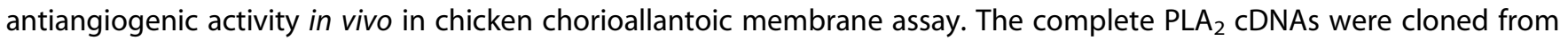
a venom gland CDNA library. Mature CC-PLA2-1 and CC-PLA2-2 contain 121 and 120 amino acids, respectively, including 14 cysteines each and showed $83 \%$ identity. Tertiary model structures of CC-PLA2-1 and CC-PLA2-2 were generated by homology modeling. This is thus the first study describing an antiangiogenic effect for snake venom $\mathrm{PLA}_{2} \mathrm{~s}$ and reporting first clues to their mechanism of action on endothelial cells.

Laboratory Investigation (2010) 90, 510-519; doi:10.1038/labinvest.2009.137; published online 8 February 2010

KEYWORDS: angiogenesis; PLA $_{2}$; integrin; chorioallantoic membrane assay; migration; adhesion

Angiogenesis is fundamental to normal healing, reproduction and embryonic development. However, this process is also important in the pathogenesis of a broad range of disorders such as arthritis and cancer. ${ }^{1}$ Angiogenesis is thus required to sustain malignant cells with nutrients and oxygen for tumors to grow beyond a microscopic size. The development of new blood vessels in the tumor also facilitates metastasis formation by providing a mechanism to increase the likelihood of tumor cells entering the blood circulation. Thus, the microvascular endothelial cell recruited by a tumor is an important target in cancer therapy and has the advantage of being genetically stable. Therefore, treating both the cancer cell and the endothelial cell in a tumor may be more effective than treating the cancer cell alone. ${ }^{2}$

Angiogenesis is a complex process, typically consisting of enzymatic degradation of the basement membrane, vascular endothelial cell migration into perivascular space, prolifera- tion and alignment to form capillary-like structures, and new vessel formation. All these events are supported by the action of the integrin adhesion receptors. ${ }^{3}$ Integrins are heterodimeric, transmembrane glycoproteins that are involved in cell-extracellular matrix (ECM) and sometimes in cell-cell adhesion. Integrins are composed of noncovalently associated $\alpha$ - and $\beta$-subunits that can assemble into at least 24 known distinct integrins, and heterodimer composition generally confers ligand specificity. ${ }^{4}$ In addition to their structural role as bridges between the ECM proteins and the actin cytoskeleton, integrins also have a critical role in signal transduction events that regulate cell shape, survival, proliferation and migration. ${ }^{5}$

Snake venom contains components able to disrupt cellECM interactions. Among these molecules, disintegrins are the most widely characterized and they are now studied for potential use in medicine (for a review, see McLane et $a l^{6}$ ).

\footnotetext{
${ }^{1}$ Laboratoire des Venins et Toxines, Institut Pasteur de Tunis, Tunis, Tunisie; ${ }^{2}$ Faculté de Pharmacie, INSERM UMR 911, CRO2, Aix-Marseille Université, Marseille, France; ${ }^{3}$ Laboratoire de Biochimie et de Génie Enzymatique des Lipases, ENIS, Sfax, Tunisie and ${ }^{4}$ Faculté de Médecine de Tunis, Tunis, Tunisie Correspondence: Dr J Luis, PhD, Faculté de Pharmacie, INSERM U911, CRO2, 27, Bd J Moulin, 13385 Marseille Cedex 5, France. E-mail: jose.luis@pharmacie.univ-mrs.fr 
Most disintegrins contain an Arg-Gly-Asp (RGD) or RGDlike sequence in the C-terminal half of the molecule, which is essential to their ability to block integrin interaction with ligands. ${ }^{7}$ Another family of venom peptides, the C-type lectin proteins (CLPs), ${ }^{8}$ has also been reported to impair cell-ECM interactions. They inhibit cell adhesion, migration, proliferation and angiogenesis by interacting with integrins. ${ }^{9-12}$

Phospholipases A2 (PLA, EC 3.1.1.4) are generally $\mathrm{Ca}^{2+}$-dependent enzymes that catalyze the hydrolysis of the sn-2 fatty acyl bond of glycerophospholipids. Secreted $\mathrm{PLA}_{2} \mathrm{~S}$ are small proteins $(14-18 \mathrm{kDa})$ usually containing 5-8 disulfide bonds and possessing a His/Asp dyad required for catalysis. ${ }^{13}$ Snake venoms contain high amounts of secreted $\mathrm{PLA}_{2} \mathrm{~S}$ that belong to either group I (elapid and hydrophid venoms) or group II (viperid and crotalid venoms). In addition to their possible role in the digestion of preys, snake venom $\mathrm{PLA}_{2} \mathrm{~s}$ exhibit a wide spectrum of pharmacological effects by interfering in normal physiological processes. They include neurotoxicity, myotoxicity, hemolytic activity, anticoagulant and antiplatelet effects (see $\mathrm{Kini}^{14}$ for a review). Furthermore, they can show antiviral and bactericidal properties. ${ }^{15-17}$ Several lines of evidence indicate that, in many instances, these effects are independent of the catalytic phospholipid hydrolysis. Moreover, to explain the susceptibility of a tissue to a particular $\mathrm{PLA}_{2}$, it has been proposed that venom $\mathrm{PLA}_{2}$ s have selective membrane-binding sites that direct them to specific cellular targets, and that such binding is crucial in their mechanism of action. ${ }^{14}$

In this work we reported in vitro and in vivo antiangiogenic activities of two secreted $\mathrm{PLA}_{2}$ S (CC-PLA2-1 and CC-PLA2-2) isolated from Cerastes cerastes venom, the Tunisian horned viper. We showed that their effect is likely due to the inhibition of $\alpha 5 \beta 1$ and $\alpha \mathrm{v}$-containing integrins.

\section{MATERIALS AND METHODS Reagents}

Venom was collected from C. cerastes snake in the Pasteur Institute's serpentarium (Tunis, Tunisia) and stored at $-20^{\circ} \mathrm{C}$. Dulbecco's modified Eagle's medium (DMEM) and RPMI 1640 medium were purchased from Lonza (LevalloisPerret, France), fetal calf serum (FCS) and horse serum were from Invitrogen (Cergy-Pontoise, France), and endothelial cell growth supplement (ECGS) was from BD Biosciences (Le Pont de Claix, France). Poly-L-lysine, human fibrinogen and mouse laminin-1 were from Sigma (St Quentin Fallavier, France). Rat type I collagen was from Upstate (Lake Placid, NY, USA) and human fibronectin from Millipore (St Quentin en Yvelines, France). Human vitronectin was purified according to Yatogho et al. ${ }^{18}$

Rat monoclonal antibody (mAb) 69.6.5 against $\alpha \mathrm{v}$ integrin was produced as previously described. ${ }^{19}$ Mouse mAbs FB12 (anti- $\alpha$ 1), P1B5 (anti- $\alpha 3$ ), P1D6 (anti- $\alpha 5)$, LM609 (anti- $\alpha \mathrm{v} \beta 3$ ) and P1F6 (anti- $\alpha \mathrm{v} \beta 5$ ) were purchased from Millipore. Mouse mAbs Gi9 (anti- $\alpha 2 \beta 1$ ), Lia1/2 (anti- $\beta 1$ ) and rat $\mathrm{mAb} \mathrm{GoH} 3$ (anti- $\alpha 6$ ) were from Beckman Coulter (Marseille, France).

\section{Cell Culture}

Human colonic adenocarcinoma (HT29-D4) $)^{20}$ and fibrosarcoma (HT1080) (ATCC) cells were routinely cultured in DMEM containing 10\% FCS. Human leukemia (K562; ATCC) and ovarian adenocarcinoma (IGROV1) cells, provided by Dr J Benard (Institut Gustave Roussy, Villejuif, France) were cultured in RPMI 1640 medium containing $10 \%$ FCS. Rat pheochromocytoma (PC12; ATCC) cells were cultured in DMEM supplemented with 5\% FCS and 10\% heat-inactivated horse serum. Immortalized human brain microvascular endothelial cells (HBMECs), kindly provided by Dr K Kim (JHU, Baltimore, MA, USA), were maintained in RPMI 1640, 20\% heat-inactivated FCS, ECGS $(50 \mu \mathrm{g} / \mathrm{ml})$, heparin $(50 \mathrm{U} / \mathrm{ml})$ and L-glutamine $(2 \mathrm{mM})$.

\section{Cell Adhesion and Migration Assays}

Adhesion assays were performed as previously described. ${ }^{21}$ Briefly, cells in single-cell suspension were added to wells coated with purified ECM proteins and allowed to adhere to the substrata for $1 \mathrm{~h}$ (HBMEC, HT1080, IGROV1 and PC12 cells) or $2 \mathrm{~h}$ (HT29-D4 and K562 cells) at $37^{\circ} \mathrm{C}$. Incubation of K562 cells was performed in the presence of $1 \mathrm{mM} \mathrm{MnCl}_{2}$ and $100 \mathrm{nM}$ phorbol 12-myristate 13-acetate (PMA) to activate $\alpha 5 \beta 1$ integrin. After washing, attached cells were fixed, stained by $0.1 \%$ crystal violet and lysed with $1 \%$ SDS. Absorbance was then measured at $600 \mathrm{~nm}$.

In vitro cell migration was evaluated using haptotaxis assays in modified Boyden chambers (NeuroProbe Inc., Bethesda, MD, USA) as previously described ${ }^{21}$ in the presence of DMEM $/ 10 \%$ FCS. After staining cells with $0.1 \%$ crystal violet, cell migration was quantified by measure of absorbance at $600 \mathrm{~nm}$.

\section{Solid-Phase Receptor Assay}

Microtiter plates (96-well) were precoated with $0.5 \mu \mathrm{g}$ CC-PLA2 for $2 \mathrm{~h}$ at $37^{\circ} \mathrm{C}$, then blocked with PBS $/ 3 \%$ BSA, overnight at $4^{\circ} \mathrm{C}$. HBMECs were solubilized with $20 \mathrm{mM}$ Tris-HCl (pH 7.6), $200 \mathrm{mM} \mathrm{NaCl}, 1 \mathrm{mM}$ EDTA, $1 \%$ Triton $\mathrm{X}-100,0.5 \% \mathrm{BSA}$ and a mixture of protease inhibitors $(1 \mathrm{mM}$ PMSF, $500 \mathrm{U} / \mathrm{ml}$ aprotinin, $1 \mu \mathrm{g} / \mathrm{ml}$ leupeptin, $1 \mu \mathrm{M}$ pepstatin, $1 \mathrm{mM}$ iodoacetamide and $1 \mathrm{mM}$ o-phenanthroline) for $30 \mathrm{~min}$ at $4^{\circ} \mathrm{C}$. The extract was clarified by centrifugation at $10000 \mathrm{~g}$ for $10 \mathrm{~min}$ at $4^{\circ} \mathrm{C}$ and then added $(200 \mu \mathrm{g}$ of total proteins) to CC-PLA2-coated wells for $4 \mathrm{~h}$ at $4^{\circ} \mathrm{C}$. Unbound proteins were removed by three washes with $\mathrm{PBS} / 0.1 \%$ Triton $\mathrm{X}-100$. Integrins binding was detected by sequential incubations with $100 \mu \mathrm{l}$ of $10 \mu \mathrm{g} / \mathrm{ml}$ mouse mAbs AMF-7 (anti- $\alpha \mathrm{v}$ ), Sam-1 (anti- $\alpha 5 \beta 1$ ) or Gi9 (anti- $\alpha 2 \beta 1$ ) and with sheep antimouse IgG HRP-conjugated antibodies for $1 \mathrm{~h}$ at room temperature. Finally, $100 \mu \mathrm{l}$ of peroxidase substrate $\left(3,3^{\prime}, 5,5^{\prime}\right.$ tetramethylbenzidine) were added for $10 \mathrm{~min}$ at room 
temperature, the reaction was stopped by adding $50 \mu \mathrm{l}$ of $1 \mathrm{~mol} / 1 \mathrm{H}_{2} \mathrm{SO}_{4}$ and absorbance was measured at $450 \mathrm{~nm}$.

\section{Chemical Inhibition of PLA Activity}

Chemical modification of CC-PLA2-1 and CC-PLA2-2 enzymes by p-bromophenacyl bromide (BPB) and enzymatic activity measurements were performed as described. ${ }^{22}$

\section{Tubulogenesis on Matrigel ${ }^{\mathrm{TM}}$ and Chicken Chorioallantoic Membrane Assay}

Tubulogenesis assays were performed using HBMEC cells on Matrigel-coated wells as already described. ${ }^{11}$ The capillarylike structures formed in the gel were quantified using ImageJ software.

Chick embryos from 3-day-old eggs were opened and placed in double Petri dishes with water for humidity. After 5 days at $37^{\circ} \mathrm{C}$, filter paper disks (diameter $6 \mathrm{~mm}$ ) soaked in buffer $(0.9 \% \mathrm{NaCl})$ or CC-PLA2-1 or CC-PLA2-2 (0.5 or $1 \mu \mathrm{M})$ were applied on the chicken chorioallantoic membrane (CAM). After $48 \mathrm{~h}$, spontaneous angiogenesis was observed and photographed with a digital camera at $\times 10$ magnification.

To check the effect of CC-PLA2-1 and CC-PLA2-2 on growth factor-induced angiogenesis, bFGF or vascular endothelial growth factor (VEGF) (200 ng per embryo)impregnated filter disks were administered topically on the CAM of 8-day-old embryos. After $24 \mathrm{~h}, \mathrm{CC}$-PLA2-1 and CCPLA2-2 $(1 \mu \mathrm{M})$ were applied to the CAM and blood vessels were photographed after $72 \mathrm{~h}$ of incubation.

\section{cDNA Library Construction and Clones Screening}

The first strand of cDNA was reverse-transcribed by a standard method according to the manufacturer's instructions (Promega) using the universal oligo(dT)-containing adapter primer 5'-CCAGTGAGCAGAGTGACGAGGACTCGAGCTC AAGCTT $_{16}-3^{\prime}$ (Proligo). $12 \mu \mathrm{l}$ of $0.1 \%$ diethylpyrocarbonatetreated water containing $0.1 \mu \mathrm{g}$ of primer and $1 \mu \mathrm{g}$ of total venom gland RNA were heated to $70^{\circ} \mathrm{C}$ for $10 \mathrm{~min}$ to denature any possible secondary structure, cooled in ice and mixed with $4 \mu \mathrm{l}$ of $5 \times$ First Strand Buffer, $2 \mu \mathrm{l}$ of $0.1 \mathrm{M}$ dithiothreitol, $1 \mu$ l of RNAsin (ribonuclease inhibitor at $40 \mathrm{U} /$ $\mu \mathrm{l}), 1 \mu \mathrm{l}$ of dNTP (10 mM each) and $200 \mathrm{U}$ RNase $\mathrm{H}$-free Moloney murine leukemia virus reverse transcriptase. The reaction mixture was incubated at $42^{\circ} \mathrm{C}$ for $1 \mathrm{~h}$, followed by $10 \mathrm{~min}$ at $95^{\circ} \mathrm{C}$ to inactivate the enzyme.

CC-PLA2 encoding sequences were amplified by PCR using venom gland cDNAs as template and the following primers: $5^{\prime}$-TCTGGATTCGGGAGGATGAGG-3' (forward primer, corresponding to highly conserved $5^{\prime}$ untranslated region of reported cDNA sequences encoding group II $\mathrm{PLA}_{2} \mathrm{~s}$ ) and $5^{\prime}$-GAGGACTCGAGCTCAAGC-3' (reverse primer, which is contained in the oligo(dT) primer). The PCR protocol included an initial denaturation step at $95^{\circ} \mathrm{C}$ for 5 min followed by 35 cycles of denaturation $\left(1 \mathrm{~min}\right.$ at $\left.95^{\circ} \mathrm{C}\right)$, annealing $\left(1 \mathrm{~min}\right.$ at $\left.55^{\circ} \mathrm{C}\right)$ and extension $\left(1 \mathrm{~min}\right.$ at $\left.72^{\circ} \mathrm{C}\right)$, and a final extension step of $7 \mathrm{~min}$ at $72^{\circ} \mathrm{C}$. The amplified fragments were separated on $1 \%$ agarose gel electrophoresis, purified using QIAquick gel extraction kit (Qiagen) and cloned into pGEM-T vector (Promega) before transforming Escherichia coli MOSBlue cells.

Positive clones, selected by growing the transformed cells in Luria Broth medium containing $10 \mu \mathrm{g} / \mathrm{ml}$ ampicillin, were confirmed by PCR amplification using the above primers and sequencing of the inserts on an Applied Biosystems model 377 DNA sequencer.

\section{Molecular Modeling}

Tertiary model structures of CC-PLA2-1 and CC-PLA2-2 were generated by homology modeling with the program Modeller 9v2. ${ }^{23}$ Homologous polypeptides with known structures were identified by a Blast2 search of the PDB database (RCSB organization) using the sequence of CC-PLA2-1 and CC-PLA2-2 as entry. The solution structures of phospholipase $\mathrm{A}_{2}$ inhibitor from Vipoxin (PDB code 1VPI) and Rv4/Rv7 complexes (PDB code 1OQ5) were used as templates. A total of 20 models were generated for each protein. All their pdb files were analyzed for their energetic and geometric characteristics. For each protein, only one model combining the best Ramachandran plot (http://swift.cmbi. $\mathrm{ru.nl} /$ servers/html//ramaplot.html), and good scores for the objective function values, ${ }^{23}$ and the VICTOR/FRST energy function proposed by Tosatto ${ }^{24}$ (http://protein.cribi.unipd.it/ frst/) was considered. The best models were then visualized with the ViewerLite50 program (http://www.accelrys.com/ products/dstudio/).

\section{RESULTS}

\section{Molecular Cloning of CC-PLA2-1 and CC-PLA2-2 and Sequences Analysis}

We recently purified to homogeneity and partially sequenced two nontoxic $\mathrm{PLA}_{2} \mathrm{~s}$ with a relatively high enzymatic activity from $C$. cerastes snake venom. These enzymes, named CCPLA2-1 and CC-PLA2-2, inhibited blood coagulation, platelet aggregation, and tumor cell adhesion and migration. ${ }^{22}$ In this study, we cloned the cDNAs encoding $\mathrm{PLA}_{2}$ isoforms from a $C$. cerastes venom gland cDNA library, amplified by PCR and sequenced.

Among the clones obtained, we retained two cDNAs that showed a complete identity with the N-terminal amino-acid sequences of purified CC-PLA ${ }_{2} \mathrm{~S}$ as determined by Edman degradation (Figure 1a, underlined). Both nucleotide sequences were deposited in GenBank under the accession numbers FJ754186 (CC-PLA2-1) and FJ754187 (CC-PLA22 ). The cDNAs contain open reading frames of 411 and $408 \mathrm{bp}$ that encode two polypeptides of 137 and 136 aminoacid residues, respectively, including a 16 amino-acid signal peptide (Figure 1a). Mature CC-PLA2-1 and CC-PLA2-2 thus contain, respectively, 121 and 120 amino acids, including 14 cysteines each. The peptide sequences of CC-PLA2-1 and CC-PLA2-2 are very similar ( $83 \%$ identity). Indeed, they 
a

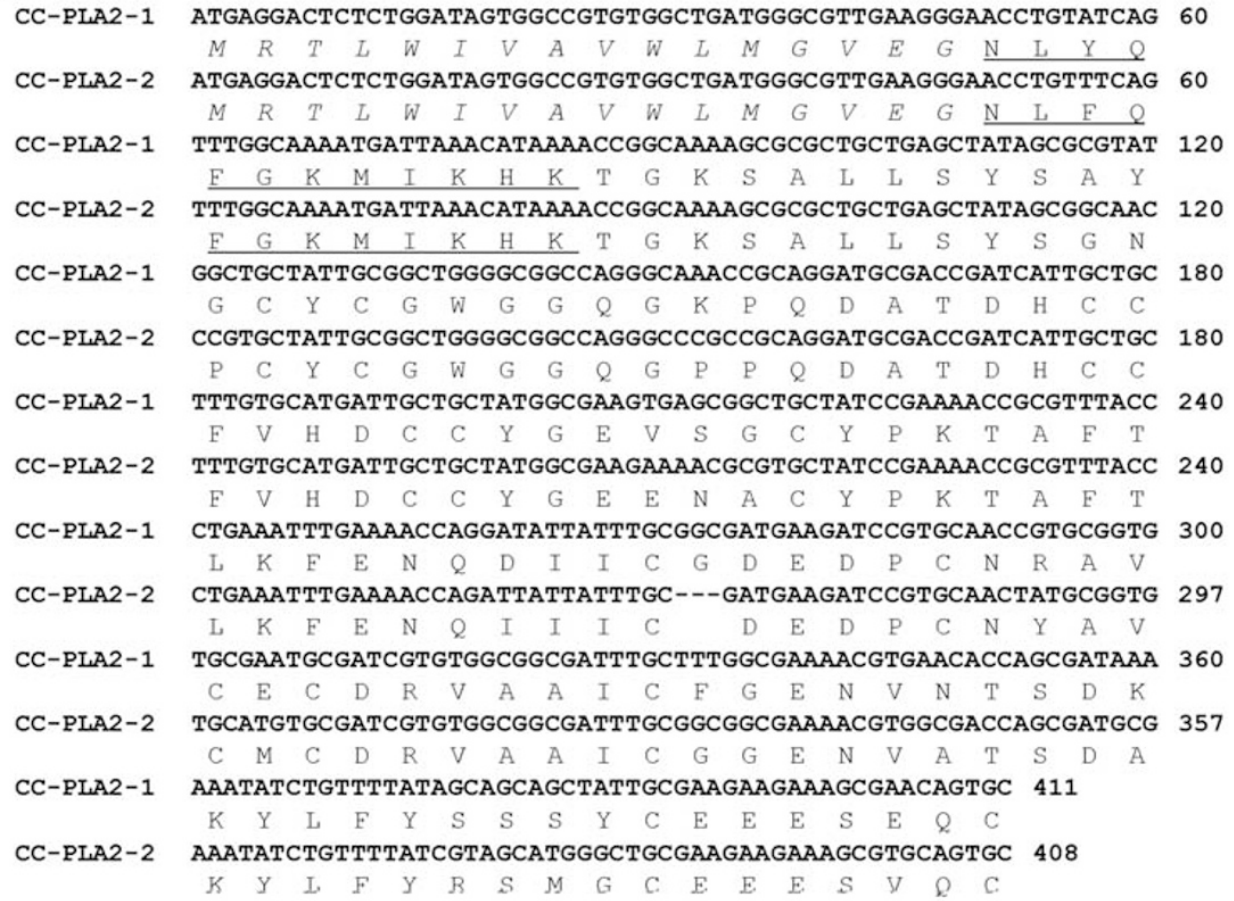

Figure 1 Molecular cloning of CC-PLA2-1 and CC-PLA2-2 and sequences alignment. (a) CDNA sequences and deduced amino-acid sequences of CC-PLA2-1 and CC-PLA2-2. The signal peptide consisting of 16 amino-acid residues is showed in italic. The $\mathrm{N}$-terminal amino-acid sequences obtained by Edman degradation of purified CC-PLA2-1 and CC-PLA2-2 are underlined. GenBank accession numbers are FJ754186 (CC-PLA2-1) and FJ754187 (CC-PLA2-2). (b) Sequence alignment of the two CC-PLA2s with other members of the snake venom PLA ${ }_{2} \mathrm{~s}$ family (NCBI accession number in bracket): EC1 PLA2 (Q90ZZ9) from Echis coloratis, ammodytin I2 (D) (CAE47222) from Vipera ursinii, PLA2-CERCE (P21789) from Cerastes cerastes, RV7 (P31100) from Daboia russelli siamensis and KDR-bp (PO4361) from Agkistrodon piscivorus piscivorus.

only show 18 amino acids and 1 deletion at position 91 in CC-PLA2-2 sequence. The calculated molecular mass of CC-PLA2-1 and CC-PLA2-2 is 13521.51 and $13259.42 \mathrm{Da}$, respectively. These values are slightly lower than those determined by mass spectrometry $(13737.52$ and $13705.63 \mathrm{Da}$, respectively), likely due to the presence of saccharide residues. ${ }^{22}$ The theoretical isoelectric points, estimated by the
Expasy tools (http://expasy.org/tools/pi_tool.html), were of 4.92 and 4.86 for CC-PLA2-1 and CC-PLA2-2, respectively.

Blast search and amino-acid sequence alignment show that the two CC-PLA ${ }_{2}$ s have a high sequence identity with group IIA snake venom $\mathrm{PLA}_{2} \mathrm{~s}$ (Figure 1b). The highest amino-acid identity with CC-PLA2-1 was observed with EC1 PLA2 from Echis coloratus snake venom (75\%), ammodytin I2 (D) 
isoform from Vipera ursinii (75\%), PLA2-CERCE from Pakistani C. cerastes (64\%) and RV7 from Daboia russelii siamensis (62\%). CC-PLA2-1 sequence also showed 45\% identity with KDR-bp, a KDR binding $\mathrm{PLA}_{2}$ from Agkistrodon piscivorus (Figure 1b).

\section{CC-PLA2-1 and CC-PLA2-2 Affect Adhesion and Migration of Endothelial Cells}

Although it has been reported that snake venom $\mathrm{PLA}_{2} \mathrm{~S}$ exert a cytotoxic activity on tumor cells, ${ }^{17,25}$ we showed that the two CC-PLA2s are not cytotoxic on human fibrosarcoma (HT1080) and melanoma (IGR39) cell lines. ${ }^{22}$ In this study, we used HBMECs to check the effect of CC-PLA2s on angiogenesis. We observed that none of the CC-PLA2s, at $1 \mu \mathrm{M}$, neither induced cell death (data not shown), nor inhibited cell growth after 4 days in culture (Figure 2a). However, both CC-PLA2s affected cell adhesion depending on the purified ECM protein used as substratum (Figure 2b). Both CCPLA2-1 and CC-PLA2-2 at $1 \mu \mathrm{M}$ abolished the attachment of HBMEC to fibrinogen and dramatically reduced their adhesion to fibronectin, whereas no effect was observed on type I collagen, vitronectin or laminin 1 . The inhibition likely involved the integrin family of adhesion receptors, as adhesion of HBMEC was not affected when using the integrinindependent substratum poly-L-lysine. Both CC-PLA2-1 and
CC-PLA2-2 inhibited cell attachment in a dose-dependent manner (Figure $2 \mathrm{c}$ ). The $\mathrm{IC}_{50}$ values were, respectively, 0.12 and $0.20 \mu \mathrm{M}$ for fibrinogen and 0.12 and $0.30 \mu \mathrm{M}$ for fibronectin.

Moreover, as already observed with tumor cells, ${ }^{22}$ alkylated CC-PLA2s were still able to inhibit HBMEC adhesion as efficiently as the active enzymes, indicating a clear dissociation of the anti-adhesive effect of CC-PLA2s and their catalytic activity (Figure $2 \mathrm{~d}$ ).

Cell migration can be considered as a finely regulated process including successive steps of cell adhesion and de-adhesion. Because CC-PLA2s block HBMEC cell adhesion, we also looked at their effect on cell migration using haptotaxis assays in modified Boyden chambers. As illustrated in Figure 3a, both CC-PLA2s at $1 \mu \mathrm{M}$ completely blocked HBMEC cell migration toward fibronectin. The inhibitory effect of CC-PLA2s on cell migration to fibronectin and to fibrinogen was dose dependent, with an inhibition of 50-65\% at a concentration as low as $0.1 \mu \mathrm{M}$ (Figure 3b).

\section{CC-PLA2-1 and CC-PLA2-2 Effects are Mediated by $\alpha 5 \beta 1$ and $\alpha \mathbf{v}$ Integrins}

Because HBMEC adhere on fibrinogen and fibronectin through $\alpha 5 \beta 1$ and $\alpha \mathrm{v}$-containing integrins (see Supplementary Figure S1), these integrins are good candidate targets for
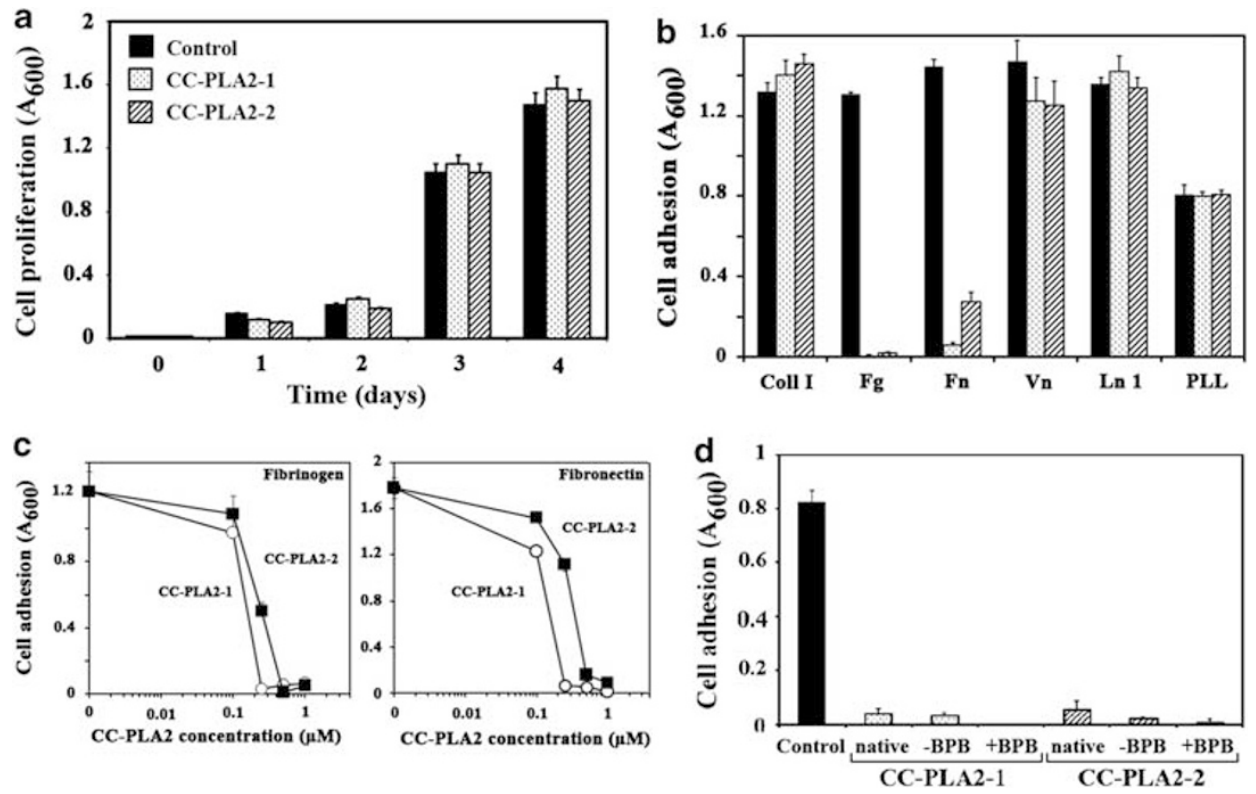

Figure 2 CC-PLA2-1 and CC-PLA2-2 inhibit endothelial cells adhesion. (a) HBMEC were seeded at 5000 cells per well and allowed to spread for $2 \mathrm{~h}$ at $37^{\circ} \mathrm{C}$.

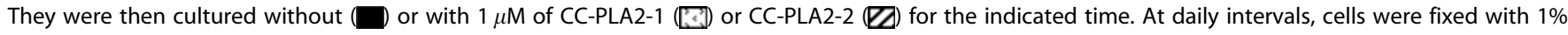
glutaraldehyde, stained with $0.1 \%$ crystal violet, solubilized by SDS and absorbance was measured at $600 \mathrm{~nm}$. (b) HBMEC were preincubated without ( $\square$ ) or with $0.5 \mu \mathrm{M}$ of CC-PLA2-1 ([;) or CC-PLA2-2 (Z) for $30 \mathrm{~min}$ at room temperature. Cells were then added to 96 -well microtiter plates coated with $10 \mu \mathrm{g} / \mathrm{ml}$ type I collagen (Coll I), fibronectin (Fn), vitronectin (Vn) or laminin-1 (Ln 1), or with $50 \mu \mathrm{g} / \mathrm{ml}$ fibrinogen (Fg) or poly-L-lysine (PLL) and allowed to adhere for $1 \mathrm{~h}$ at $37^{\circ} \mathrm{C}$. After washing, adherent cells were fixed, stained with crystal violet, solubilized by SDS and absorbance was measured at $600 \mathrm{~nm}$. (c) HBMECs were preincubated with the indicated concentrations of CC-PLA2-1 (-م) or CC-PLA2-2 (- - ) and allowed to adhere to plates coated with fibrinogen or fibronectin as described above. (d) HBMECs were preincubated without (control) or with $1 \mu \mathrm{M}$ of purified CC-PLA2-1 or CC-PLA2-2 (native) or with enzymes previously chemically treated in the absence $(-\mathrm{BPB})$ or in the presence $(+\mathrm{BPB})$ of p-bromophenacyl bromide. Cells were then allowed to adhere to plates coated with fibrinogen as described above. All data shown are means ( \pm s.d.) from at least three experiments performed in triplicate. 

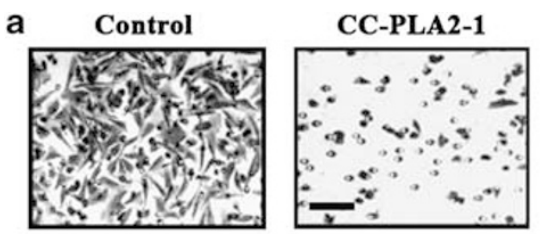

b

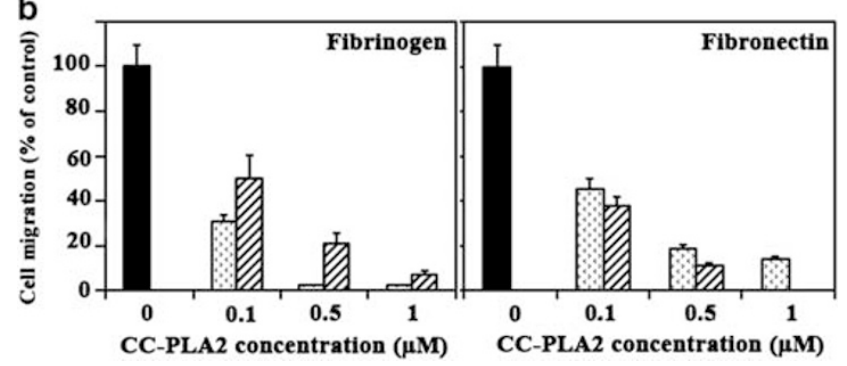

Figure 3 CC-PLA2-1 and CC-PLA2-2 inhibit endothelial cell migration. (a) HBMECs were treated for $30 \mathrm{~min}$ at room temperature with $1 \mu \mathrm{M}$ CC-PLA2s and then added into the upper reservoir of a modified Boyden chamber with porous membrane precoated with $10 \mu \mathrm{g} / \mathrm{ml}$ fibronectin. After incubation at $37^{\circ} \mathrm{C}$ for $5 \mathrm{~h}$, cells that migrated to the underside of the filter were stained with $0.1 \%$ crystal violet. Scale bar $=100 \mu \mathrm{m}$. (b) HBMECs were treated without $(\square$ ) or with $0.1,0.5$ or $1 \mu \mathrm{M}$ of CC-PLA2-1 (G) or CC-PLA2-2 $(\mathbb{Z})$ and migration to fibrinogen or to fibronectin was quantified as described above. Data shown ( \pm s.d.) are from one experiment representative of three performed in triplicate. They are expressed as a percentage of adhesion in the absence of CC-PLA2s.

the inhibitory effects of CC-PLA2s. To test this supposition, we conducted several assays. We first performed adhesion assays to immobilized CC-PLA2s in the presence of blocking antibodies directed against various integrin subunits. As illustrated in Figure 4a, both CC-PLA2s were efficient in allowing HBMEC attachment. Antibodies against $\alpha \mathrm{v}$ integrin subunit completely abolished cell adhesion to CC-PLA2s, whereas antibodies against $\alpha \mathrm{v} \beta 3$ reduced cell attachment by about $75-80 \%$, suggesting that $\alpha \mathrm{v}$ integrins may be involved.

We next checked the anti-adhesive effect of CC-PLA2s on various cell/ECM protein pairs involving each one a sole integrin: $\alpha 1 \beta 1$ (PC12/type IV collagen), $\alpha 2 \beta 1$ (HT1080/type I collagen), $\alpha 5 \beta 1$ (K562/fibronectin), $\alpha 6 \beta 4$ (HT29-D4/laminin-1), $\quad \alpha \mathrm{v} \beta 3$ (IGROV1/fibrinogen), $\alpha \mathrm{v} \beta 5$ (HT29-D4/vitronectin) and $\alpha \mathrm{v} \beta 6$ (HT29-D4/fibronectin). As shown in Figure $4 \mathrm{~b}$, none of the CC-PLA2s modified cell adhesion through $\alpha 1 \beta 1, \alpha 2 \beta 1, \alpha 6 \beta 4$ or $\alpha \mathrm{v} \beta 5$ integrins. However, both $\mathrm{PLA}_{2} \mathrm{~s}$ efficiently blocked the adhesive function of $\alpha 5 \beta 1, \alpha \mathrm{v} \beta 3$ and $\alpha \mathrm{v} \beta 6$ integrins.

The integrin adhesive function can be regulated by subcellular relocalization or by intracellular signals, a phenomenon known as inside-out signaling. We therefore used a solid-phase binding assay to test the interaction of the integrins with immobilized CC-PLA2 in a cell-free environment. In these conditions, we observed that solubilized $\alpha \mathrm{v}$ and $\alpha 5 \beta 1$ integrins still bound to both CC-PLA2s, whereas binding of $\alpha 2 \beta 1$ integrin was very low (Figure $4 \mathrm{c}$ ). Altogether these results suggest that CC-PLA2s likely inhibit cell adhesion and migration by interacting directly with $\alpha \mathrm{v}$ and $\alpha 5 \beta 1$ integrins.

\section{CC-PLA2-1 and CC-PLA2-2 Display in vitro and in vivo Antiangiogenic Activity}

Cell adhesion and migration are integral parts of the angiogenic process and affect tubulogenesis. Because HBMEC tubulogenesis can be inhibited by specific anti- $\alpha \mathrm{v}$ antibodies and by $\mathrm{C}$-type lectins that target $\alpha \mathrm{v}$-containing integrins, ${ }^{11}$ we hypothesized that $\mathrm{PLA}_{2}$-mediated impairment of HBMEC adhesion and migration could therefore affect tubulogenesis. HBMECs were thus treated with $1 \mu \mathrm{M}$ of CC-PLA2 and in vitro tubulogenesis assays were performed on Matrigel. As shown in Figure 5A, both CC-PLA2s completely blocked in vitro tubulogenesis. Besides, this effect was dose dependent (Figure 5B).

To further characterize the antiangiogenic properties of CC-PLA2s, we used the in vivo CAM assay. Both CC-PLA2-1 and CC-PLA2-2 $(1 \mu \mathrm{M})$ strongly reduced vasculature development. A marked reduction in the number of new capillaries and branching, without affecting the mature blood vessels, was also observed (Figure 5C, b and c). Quantification shows that the total vessel length was reduced by 76 and $78 \%$ for CC-PLA2-1 and CC-PLA2-2, respectively, compared with the untreated conditions (Figure 5D). Chicken CAM assays were also performed under the induction of angiogenesis by bFGF or VEGF (200 ng per embryo) with or without the addition of CC-PLA2. Either bFGF or VEGF induced a pronounced angiogenic response in this model (Figure 5C, d and g, respectively). Both CC-PLA2-1 and CC-PLA2-2 reduced by $54 \%$ the bFGF-induced angiogenesis (Figure 5C, e and f; Figure 5D). CC-PLA2-1 and CC-PLA2-2 also reduced by 60 and $66 \%$, respectively, VEGF-induced angiogenesis (Figure 5C, h and j; Figure 5D). Consequently, we can conclude that both CC-PLA2s are able to block normal as well as induced angiogenesis in vitro and in vivo.

\section{Molecular Modeling of CC-PLA2-1 and CC-PLA2-2}

The three-dimensional models of CC-PLA2-1 and CC-PLA22 , obtained using solution structures of $\mathrm{PLA}_{2}$ inhibitor from Vipoxin (PDB code 1VPI) ${ }^{26}$ and Rv4/Rv7 complex (PDB code $1 \mathrm{OQ} 5)^{27}$ as templates, were refined with suitable stereochemical parameters. Statistics for the Ramachandran plot from an analysis gave $94.2 \%$ for CC-PLA2-1 and $96.6 \%$ for CC-PLA2-2 of nonglycine residues in the most favored regions. The overall structures of CC-PLA2-1 and CC-PLA2-2 resemble that of classic group II PLA ${ }_{2}$ enzymes (Figure 6), consisting of an $\mathrm{N}$-terminal $\alpha$-helix (residues Leu ${ }^{2}$ to $\mathrm{Thr}^{13}$ ), a loop equivalent to $\mathrm{Ca}^{2+}$-binding loop $\left(\mathrm{Tyr}^{27}, \mathrm{Gly}^{29}, \mathrm{Gly}^{31}\right.$ and $\left.\mathrm{Asp}^{49}\right)$, two long antiparallel $\alpha$ helices $\left(\alpha 2\right.$, residues $\mathrm{Ala}^{39}$ to $\mathrm{Gly}^{52} ; \alpha 3$, residues $\mathrm{Pro}^{79}$ to $\left.\mathrm{Glu}^{97}\right)$, the short two-stranded antiparallel $\beta$-sheet ( $\beta$-wing) ( $\mathrm{Leu}^{65}$ to $\mathrm{Phe}^{67}$ and $\mathrm{Ile}^{72}$ to $\mathrm{Cys}^{74}$ ), and the C-terminal loop region. In this model, the 14 cysteine residues of CC-PLA2-1 and CC-PLA2-2 form seven disulfide bonds for each protein. The patterns of the disulfide 

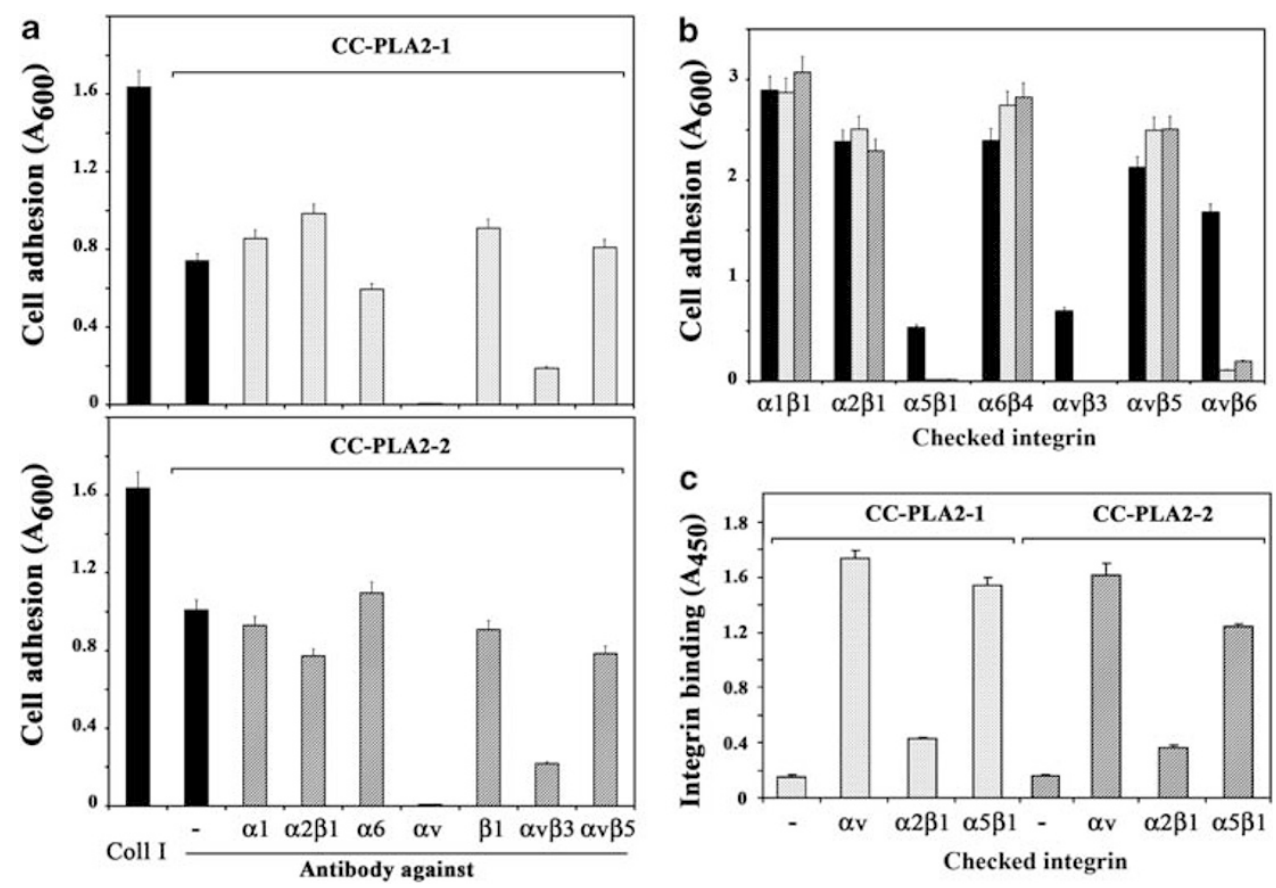

Figure 4 Anti- $\alpha 5$ and anti- $\alpha$ v antibodies inhibit cell adhesion to CC-PLA2s. (a) HBMECs were preincubated without (-) or with function-blocking antibodies against integrin subunits for $30 \mathrm{~min}$ at room temperature. Antibodies were used as follow: FB12 (anti- $\alpha 1$ ), Gi9 (anti- $\alpha 2 \beta 1$ ), GoH3 (anti- $\alpha 6$ ), 69.6 .5 (anti- $\alpha \mathrm{v}$ ), Lia1/2 (anti- $\beta 1)$ and LM609 (anti- $\alpha \mathrm{v} \beta 3$ ) at $10 \mu \mathrm{g} / \mathrm{ml}$ and P1F6 (anti- $\alpha \mathrm{v} \beta 5)$ at 1:100. Cells were then added to 96-well microtiter plates coated with $1 \mu \mathrm{M}$ CCPLA2-1 or CC-PLA2-2 for $1 \mathrm{~h}$ at $37^{\circ} \mathrm{C}$. After washing, adherent cells were stained with crystal violet, solubilized by SDS and absorbance was measured at $600 \mathrm{~nm}$. Cell adhesion to type I collagen (Coll I) is shown as a control. Data are means ( \pm s.d.) from 3-5 experiments performed in triplicate. (b) Adhesion assays were performed with various cell/ECM protein pairs involving each one a sole integrin: $\alpha 1 \beta 1$ (PC12/type IV collagen), $\alpha 2 \beta 1$ (HT1080/type I collagen), $\alpha 5 \beta 1$ (K562/fibronectin), $\alpha 6 \beta 4$ (HT29D4/laminin-1), $\alpha v \beta 3$ (IGROV1/fibrinogen), $\alpha v \beta 5$ (HT29D4/vitronectin) and $\alpha v \beta 6$ (HT29D4/fibronectin). Cells were preincubated in the absence $(\square)$ or in the presence of $1 \mu \mathrm{M} \mathrm{CC-PLA2-1} \mathrm{( \square )} \mathrm{or} \mathrm{CC-PLA2-2} \mathrm{(Z)} \mathrm{and} \mathrm{plated} \mathrm{on} \mathrm{ECM} \mathrm{protein-coated} \mathrm{wells} \mathrm{at} 37^{\circ} \mathrm{C}$ for 1 or $2 \mathrm{~h}$ depending on the cell line. Adhesion was then quantified as described above. Data shown ( \pm s.d.) are from one experiment representative of 2 or 3 performed in triplicate. (c) Solubilized proteins $(200 \mu \mathrm{g})$ from HBMEC were added to 96-well plates precoated with 0.5 $\mu$ g of CC-PLA2-1 ([']) or CC-PLA2-2 (Z). After incubation for $4 \mathrm{~h}$ at $4^{\circ} \mathrm{C}$ and extensive washing, bound integrins were detected by sequential incubations with $10 \mu \mathrm{g} / \mathrm{ml} \mathrm{mouse} \mathrm{mAbs}$ AMF-7 (anti- $\alpha \mathrm{v}$ ), Gi9 (anti- $\alpha 2 \beta 1$ ) or Sam-1 (anti- $\alpha 5 \beta 1$ ) and with sheep anti-mouse lgG HRP-conjugated antibodies for $1 \mathrm{~h}$ at room temperature. Finally, peroxidase substrate was added for $10 \mathrm{~min}$ at room temperature, the reaction was stopped by $\mathrm{H}_{2} \mathrm{SO}_{4}$ and absorbance was measured at $450 \mathrm{~nm}$.

bridges are identical to that of classic group II PLA $2\left(\mathrm{Cys}^{26}-\right.$ $\mathrm{Cys}^{113}, \mathrm{Cys}^{28}-\mathrm{Cys}^{44}$; $\mathrm{Cys}^{43}-\mathrm{Cys}^{81} ; \mathrm{Cys}^{49}-\mathrm{Cys}^{121}$, $\mathrm{Cys}^{50}-\mathrm{Cys}{ }^{86}$; $\mathrm{Cys}^{57}-\mathrm{Cys}^{79}$ and $\left.\mathrm{Cys}^{74}-\mathrm{Cys}^{84}\right)$. Other main structural features include highly conserved catalytic residues ( $\mathrm{His}^{47}, \mathrm{Tyr}^{51}$ and $\mathrm{Asp}^{89}$ ).

\section{DISCUSSION}

$\mathrm{PLA}_{2} \mathrm{~s}$ are among the best-characterized components of snake venom. In addition to their possible role in the digestion of the prey, many snake venom $\mathrm{PLA}_{2} \mathrm{~s}$ are toxic and exhibit a large variety of pharmacological effects, including tissues toxicity, modulation of platelet aggregation and hypotension. ${ }^{14}$ In this work, we demonstrated for the first time that CC-PLA2-1 and CC-PLA2-2, two snake venom PLA 2 enzymes from $C$. cerastes venom, can also exert antiangiogenic activity in vitro and in vivo. In some cases, in vivo tissue damages caused by $\mathrm{PLA}_{2} \mathrm{~s}$ have been correlated with in vitro cytotoxicity. $^{28,29}$ However, the antiangiogenic activity of CCPLA2s is likely not due to any cytotoxic effect on HBMEC cells. Indeed, endothelial cells proliferation was not affected by CC-PLA2s over a 4-day period (see Figure 2a), cells did not detach from the substratum during the test and no cell debris could be observed. Moreover, their proliferative potential was neither altered by treating cells in suspension, as performed in most of the experiments, excluding the possibility that endothelial cells undergo apoptosis secondary to anoikis (data not shown). Rather, the CC-PLA2s, used at concentrations lower than $1 \mu \mathrm{M}$, efficiently inhibit several key steps of the angiogenic process in vitro, such as endothelial cell adhesion, migration and tubulogenesis.

To the best of our knowledge, such inhibitory activities of secreted $\mathrm{PLA}_{2}$ on endothelial cells have not been reported to date. Some studies have suggested instead an increased motility of epithelial cells and an increased invasion of fibroblasts in response to Naja naja $\mathrm{PLA}_{2} \cdot{ }^{30,31}$ In the case of endothelial cells, Rizzo et $a l^{32}$ also showed evidences for a chemotactic effect of secreted $\mathrm{PLA}_{2}$. This discrepancy with our own observations may be due to the differences in the techniques, as we used haptotaxis assays to analyze cell migration. Moreover, we analyzed the effect of CC-PLA2s on 

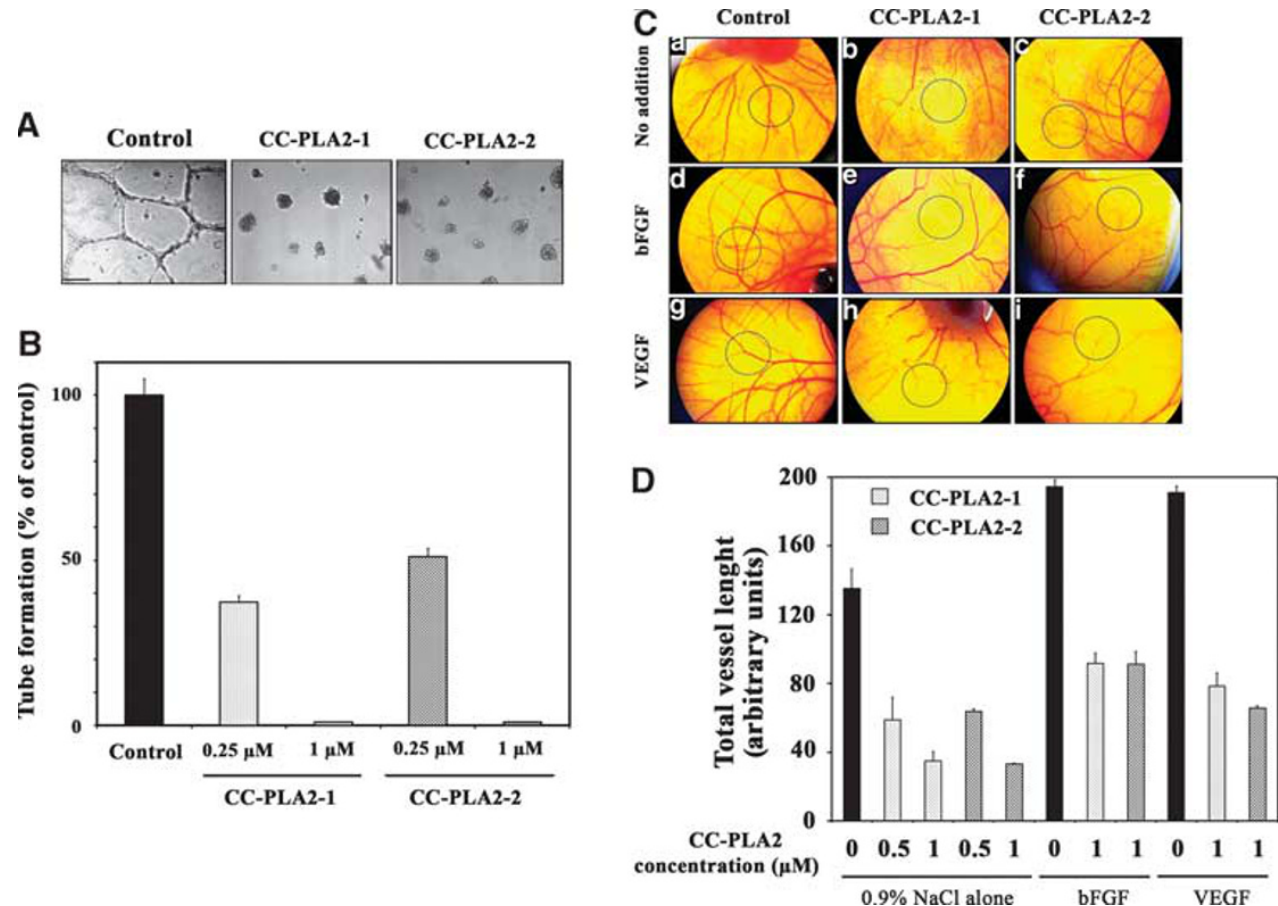

Figure 5 CC-PLA2s block in vitro and in vivo angiogenesis. (A) Representative tubulogenesis assay after pretreatment of HBMEC with $1 \mu \mathrm{M}$ CC-PLA2-1 or CC-PLA2-2 for $30 \mathrm{~min}$ at room temperature. Cells $\left(2 \times 10^{4}\right)$ were then added to the Matrigel-coated wells in culture medium and allowed to form capillarylike structures for $18 \mathrm{~h}$ at $37^{\circ} \mathrm{C}$. Scale bar $=100 \mu \mathrm{m}$. (B) Quantification of the capillary-like structures formed in the gel after treatment with the indicated concentrations of CC-PLA2-1 or CC-PLA2-2. Presented is a mean ( \pm s.d.) from at least three independent experiments. (C) The CAM models were prepared using 8-day-old chick embryos treated as described in Materials and methods. Filter disks were soaked in (a) $0.9 \% \mathrm{NaCl}$ alone; (b) $1 \mu \mathrm{M}$ CC-PLA2-1; (c) $1 \mu \mathrm{M}$ CC-PLA2-2; (d) $200 \mathrm{ng}$ bFGF; (e) $200 \mathrm{ng}$ bFGF and $1 \mu \mathrm{M}$ CC-PLA2-1, (f) $200 \mathrm{ng}$ bFGF and $1 \mu \mathrm{M}$ CC-PLA2-2; (g) $200 \mathrm{ng}$ VEGF; (h) $200 \mathrm{ng}$ VEGF and $1 \mu \mathrm{M}$ CC-PLA21 ; (i) $200 \mathrm{ng}$ VEGF and $1 \mu \mathrm{M}$ CC-PLA2-2. After incubation for $72 \mathrm{~h}$, CAMs were photographed with a digital camera. Each group contained four CAMs and the experiment was repeated three times. (D) The quantitative measurement of total vessel length was performed on $50 \%$ of the total CAM surface treated in

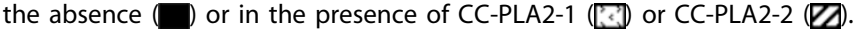

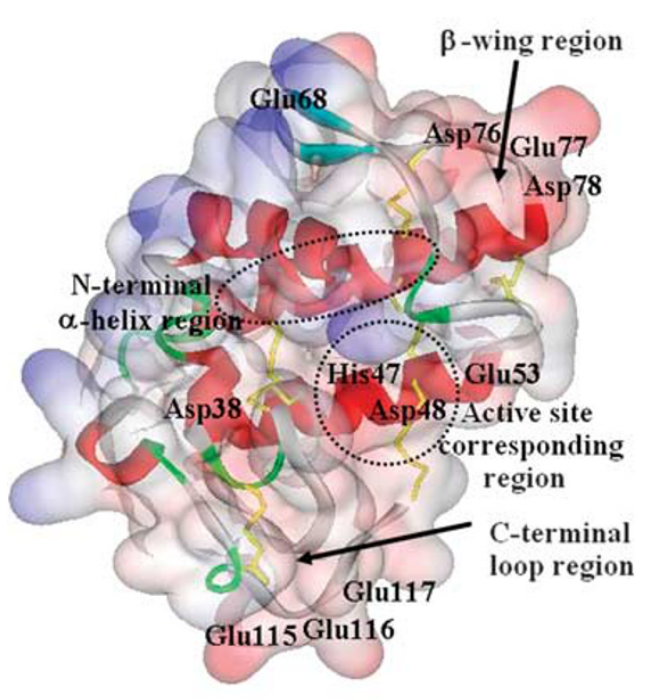

CC-PLA2-1

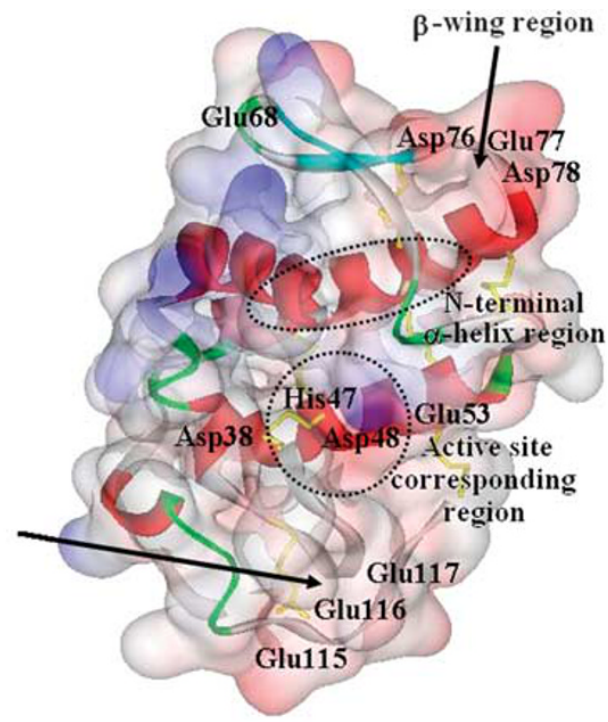

CC-PLA2-2

Figure 6 Surface electrostatic potential models for CC-PLA2-1 and CC-PLA2-2. Tertiary model structures of CC-PLA2-1 and CC-PLA2-2 were generated by homology modeling with the program Modeller $9 \mathrm{v} 2$ and visualized with the ViewerLite50 program. The dotted circles indicate $\mathrm{N}$-terminal $\alpha$-helix and active site regions. The $\beta$-wing and $\mathrm{C}$-terminal loop regions are emphasized. 
cell migration after $5 \mathrm{~h}$, a period of time giving no more chemotactic response in the case of endothelial cells. ${ }^{32}$ Alternatively, secreted $\mathrm{PLA}_{2}$ s may show tissue-specific antiangiogenic activities. This is supported by the fact that $\mathrm{PLA}_{2}$ are unable to induce migration of human vascular smooth muscle cells. ${ }^{32}$ This is also the case of sphingosine-1-phosphate, a generally proangiogenic molecule, that inhibits brain-derived endothelial cells migration and in vitro tubulogenesis. ${ }^{33}$ The physiological relevance of our in vitro findings on endothelial cells is confirmed by the blockage of in vivo angiogenesis induced by CC-PLA2s.

The inhibitory effect of CC-PLA2s on cell migration and angiogenesis is likely due to the reduced attachment to ECM proteins observed in the presence of the enzyme. As primary receptors for ECM proteins, integrins are required for cell motility. Integrins have also a major role in angiogenesis along with others promoters, such as cadherins, matrix metalloproteinases or growth factors. ${ }^{1}$ Initially, the anti-integrin activity among snake venom proteins was considered to be characteristic for disintegrins. ${ }^{34}$ However, in the last years increasing evidences show that some CLP can also inhibit integrin-dependent function. ${ }^{11,12,35}$ Here, we extend this observation to another class of snake venom proteins, the group IIA PLA $\mathrm{P}_{2}$.

That CC-PLA2-1 and CC-PLA2-2 impaired angiogenesis by interfering with integrin function is suggested by the fact that both proteins affected adhesion to ECM proteins, but not to the integrin-independent substratum poly-L-lysine. However, all integrins are likely not affected because inhibition was only observed with fibrinogen and fibronectin, but not with other integrins ligands such as type I collagen, vitronectin or laminin 1. In HBMEC, fibrinogen and fibronectin are ligands of $\alpha 5 \beta 1$ and $\alpha \mathrm{v}$-containing integrins (Supplementary Figure S1), suggesting that these receptors may be targeted by CC-PLA2s. Indeed, using blocking antibodies and various cell/ECM protein pairs, we observed that both CC-PLA2-1 and CC-PLA2-2 inhibited $\alpha 5 \beta 1$ and $\alpha \mathrm{v}$ containing integrins, while having no effect on $\alpha 1 \beta 1, \alpha 2 \beta 1$ and $\alpha 6 \beta 4$. Furthermore, CC-PLA2s are able to discriminate between $\alpha \mathrm{v}$-containing integrins, as $\alpha \mathrm{v} \beta 3$ and $\alpha \mathrm{v} \beta 6$ were inhibited, whereas $\alpha \mathrm{v} \beta 5$ was not. HBMEC cells express at their cell surface similar high levels of $\alpha \mathrm{v} \beta 3$ and $\alpha \mathrm{v} \beta 5$, two vitronectin receptors. The fact that $\alpha \mathrm{v} \beta 5$ is not inhibited by CC-PLA2s may therefore explains the quasi-absence of effect on HBMEC adhesion to vitronectin. Because each cell type shows its own repertoire of integrins, the functional redundancy of these receptors could also explain the absence of $\mathrm{PLA}_{2}$ effect reported for some cell types. ${ }^{31,32}$

The inhibitory effect of CC-PLA2s on integrin function could be either direct (eg, physical association with integrins) or indirect (through a third partner). We report in this study that integrins $\alpha \mathrm{v} \beta 3$ and $\alpha 5 \beta 1$ are still able to interact with CC-PLA2s in a cell-free assay, excluding any effect of PLA2s on integrin subcellular relocalization or activation by intracellular signals. This is in agreement with a recent report showing that secretory group IIA PLA $\mathrm{PL}_{2}$ bind to $\alpha \mathrm{v} \beta 3$ and $\alpha 4 \beta 1$ integrins and that integrin- $\mathrm{PLA}_{2}$ interactions may mediate proinflammatory activity. ${ }^{36}$

The role of $\alpha \mathrm{v} \beta 3$ in the angiogenic process is well documented, ${ }^{37}$ with $\alpha \mathrm{v} \beta 3$ expression being the most significant alteration in angiogenic endothelial cells relative to quiescent endothelium. ${ }^{3}$ In the last decade, several clinical trials evaluating the efficacy of $\alpha \mathrm{v} \beta 3$ blockers have led to encouraging results in cancer therapy and diagnosis. However, integrins $\alpha 5 \beta 1$ are also involved, as $\alpha 5$-null mouse embryos showed a marked decrease in the complexity of the vasculature when compared with wild-type embryos. ${ }^{38}$ The heterodimer $\alpha 5 \beta 1$ has also been shown to be expressed in growing vessels but its expression disappears in mature vessels. ${ }^{39}$ Consistent with this, our results showed that CC-PLA2s do not affect stable, established blood vessels on CAMs, but strongly reduce the number of new capillaries and vascular branching. Moreover, CC-PLA2s do not affect the viability of stable confluent endothelial cells in vitro.

Thus, the antiangiogenic effect of CC-PLA2s can, at least partly, be due to the blockage of the $\alpha \mathrm{v} \beta 3$ and $\alpha 5 \beta 1$ integrins function. However, inhibition of angiogenesis can also result from blockage of VEGF or its receptor. Thus, it has been recently reported that inactive $\mathrm{PLA}_{2}$ homologues, such as KDR-bp isolated from Eastern cottonmouth venom, are common antagonists of KDR, a VEGF receptor. ${ }^{40}$ Moreover, interaction with KDR involved clusters of positively charged amino acids present in the C-terminal loop (residues 115120 ) and $\beta$-wing ( Lys $^{38}$ and $\mathrm{Lys}^{53}$ ) regions of KDR-bp. ${ }^{41}$ However, as shown in surface electrostatic potential models (Figure 6), both CC-PLA2-1 and CC-PLA2-2 contain negatively charged clusters within their C-terminal loop (residues $\mathrm{Glu}^{115}$, Glu ${ }^{116}$ and $\mathrm{Glu}^{117}$ instead of Lys in KDR-pb) and $\beta$-wing ( $\mathrm{Asp}^{38}$ and $\mathrm{Glu}^{53}$ instead of Lys in KDR-pb) regions. Taken altogether, this confirms that CC-PLA2-1 and CC-PLA2-2 likely impair angiogenesis by inhibiting integrins, in particular $\alpha \mathrm{v} \beta 3$, rather than the VEGF receptor.

In conclusion, we show for the first time that two $\mathrm{PLA}_{2} \mathrm{~S}$ from snake venom are potent integrin inhibitors. These enzymes are able to block endothelial cell adhesion and migration by interfering with $\alpha 5 \beta 1$ and $\alpha \mathrm{v}$ integrins function, resulting in a blockage of angiogenesis. It could thus be interesting to confirm whether this inhibition requires physical interaction with integrins and which are the amino-acid residues involved.

Supplementary Information accompanies the paper on the Laboratory Investigation website (http://www.laboratoryinvestigation.org)

\section{ACKNOWLEDGEMENTS}

We thank Professor Hechmi Louzir, head of Institut Pasteur de Tunis, for his continuous interest in this study and for his support. We thank Benlasfar Zakaria (Laboratoire Vétérinaire, Institut Pasteur de Tunis) for providing viper venom. We also thank Dr K Kim (JHU, Baltimore, MA, USA) for giving HBMEC cells and Professor Youssef Gargouri (Laboratoire de Biochimie et de Génie Enzymatique des Lipases, Sfax, Tunisia) for his interest to this work.

We especially thank Janine Secchi for technical assistance and Dorra 
Abdelmalek for help during the preparation of this work. This work was supported in part by a grant from the Comité Mixte de Coopération Universitaire France-Tunisie (CMCU), the Conseil Régional and the Cancéropôle of Provence-Alpes-Côte d'Azur and the Tunisian Ministry of Education and Research.

\section{DISCLOSURE/CONFLICT OF INTEREST}

The authors declare no conflict of interest.

1. Folkman J. Angiogenesis: an organizing principle for drug discovery? Nat Rev Drug Discov 2007;6:273-286.

2. Alghisi GC, Ruegg C. Vascular integrins in tumor angiogenesis: mediators and therapeutic targets. Endothelium 2006;13:113-135.

3. Stupack DG, Cheresh DA. Integrins and angiogenesis. Curr Top Dev Biol 2004;64:207-238.

4. Takada Y, Ye X, Simon S. The integrins. Genome Biol 2007;8:215.

5. Delon I, Brown NH. Integrins and the actin cytoskeleton. Curr Opin Cell Biol 2007;19:43-50.

6. McLane MA, Sanchez EE, Wong A, et al. Disintegrins. Curr Drug Targets Cardiovasc Haematol Disord 2004;4:327-355.

7. Calvete JJ, Marcinkiewicz C, Monleon D, et al. Snake venom disintegrins: evolution of structure and function. Toxicon 2005:45:1063-1074.

8. Lu Q, Navdaev A, Clemetson JM, et al. Snake venom C-type lectins interacting with platelet receptors. Structure-function relationships and effects on haemostasis. Toxicon 2005;45:1089-1098.

9. Eble JA, Tuckwell DS. The $\alpha 2 \beta 1$ integrin inhibitor rhodocetin binds to the A-domain of the integrin $\alpha 2$ subunit proximal to the collagen-binding site. Biochem J 2003;376(Part 1):77-85.

10. Horii K, Okuda D, Morita T, et al. Crystal structure of EMS16 in complex with the integrin alpha2-I domain. J Mol Biol 2004;341:519-527.

11. Pilorget A, Conesa M, Sarray S, et al. Lebectin, a Macrovipera lebetina venom-derived C-type lectin, inhibits angiogenesis both in vitro and in vivo. J Cell Physiol 2007;211:307-315.

12. Sarray S, Delamarre E, Marvaldi J, et al. Lebectin and lebecetin, two C-type lectins from snake venom, inhibit $\alpha 5 \beta 1$ and $\alpha \mathrm{V}$-containing integrins. Matrix Biol 2007;26:306-313.

13. Schaloske RH, Dennis EA. The phospholipase A2 superfamily and its group numbering system. Biochim Biophys Acta 2006;1761: $1246-1259$.

14. Kini RM. Excitement ahead: structure, function and mechanism of snake venom phospholipase A2 enzymes. Toxicon 2003;42:827-840.

15. Paramo L, Lomonte B, Pizarro-Cerda J, et al. Bactericidal activity of Lys49 and Asp49 myotoxic phospholipases A2 from Bothrops asper snake venom - synthetic Lys49 myotoxin II-(115-129)-peptide identifies its bactericidal region. Eur J Biochem 1998;253:452-461.

16. Fenard D, Lambeau G, Valentin E, et al. Secreted phospholipases A(2), a new class of HIV inhibitors that block virus entry into host cells. J Clin Invest 1999;104:611-618.

17. Roberto PG, Kashima S, Marcussi S, et al. Cloning and identification of a complete CDNA coding for a bactericidal and antitumoral acidic phospholipase A2 from Bothrops jararacussu venom. Protein J 2004;23:273-285.

18. Yatogho $T$, Izumi $M$, Kashiwagi $H$, et al. Novel purification of vitronectin from human plasma by heparin affinity chromatography. Cell Str Funct 1988;13:281-292.

19. Lehmann M, Rabenandrasana C, Tamura R, et al. A monoclonal antibody inhibits adhesion to fibronectin and vitronectin of a colon carcinoma cell line and recognizes the integrins $\alpha \mathrm{v} \beta 3, \alpha \mathrm{v} \beta 5$, and $\alpha \mathrm{v} \beta 6$. Cancer Res 1994;54:2102-2107.

20. Fantini J, Abadie B, Tirard A, et al. Spontaneous and induced dome formation by two clonal cell populations derived from a human adenocarcinoma cell line HT29. J Cell Sci 1986;83:235-249.

21. Bazaa A, Luis J, Srairi-Abid N, et al. MVL-PLA2, a phospholipase A2 from Macrovipera lebetina transmediterranea venom, inhibits tumor cells adhesion and migration. Matrix Biol 2009;28: 188-193.

22. Zouari-Kessentini R, Luis J, Karray A, et al. Two purified and characterized phospholipases A2 from Cerastes cerastes venom, that inhibit cancerous cell adhesion and migration. Toxicon 2009;53: 444-453.

23. Sali A, Blundell TL. Comparative protein modelling by satisfaction of spatial restraints. J Mol Biol 1993;234:779-815.

24. Tosatto SC. The victor/FRST function for model quality estimation. J Comput Biol 2005;12:1316-1327.

25. Araya C, Lomonte B. Antitumor effects of cationic synthetic peptides derived from Lys49 phospholipase A2 homologues of snake venoms. Cell Biol Int 2007;31:263-268.

26. Devedjiev $\mathrm{Y}$, Popov A, Atanasov B, et al. X-ray structure at $1.76 \mathrm{~A}$ resolution of a polypeptide phospholipase A2 inhibitor. J Mol Biol 1997;266:160-172.

27. Perbandt $M, T$ sai $I H$, Fuchs $A$, et al. Structure of the heterodimeric neurotoxic complex viperotoxin $\mathrm{F}$ (RV-4/RV-7) from the venom of Vipera russelli formosensis at $1.9 \mathrm{~A}$ resolution. Acta Crystallogr D Biol Crystallogr 2003;59(Pt 10):1679-1687.

28. Damico DC, Nascimento JM, Lomonte B, et al. Cytotoxicity of Lachesis muta muta snake (bushmaster) venom and its purified basic phospholipase A2 (LmTX-I) in cultured cells. Toxicon 2007;49:678-692.

29. Villalobos JC, Mora R, Lomonte B, et al. Cytotoxicity induced in myotubes by a Lys 49 phospholipase A2 homologue from the venom of the snake Bothrops asper: evidence of rapid plasma membrane damage and a dual role for extracellular calcium. Toxicol In Vitro 2007;21:1382-1389.

30. Minami T, Tojo H, Zushi S, et al. Phospholipase A2 stimulates rat gastric epithelial cell line (RGM-1) migration. Inflamm Res 1997;46:103-107.

31. Kundu GC, Mukherjee AB. Evidence that porcine pancreatic phospholipase A2 via its high affinity receptor stimulates extracellular matrix invasion by normal and cancer cells. J Biol Chem 1997;272:2346-2353.

32. Rizzo MT, Nguyen $E$, Aldo-Benson $M$, et al. Secreted phospholipase $A(2)$ induces vascular endothelial cell migration. Blood 2000;96:3809-3815.

33. Pilorget $A$, Annabi $B$, Bouzeghrane $F$, et al. Inhibition of angiogenic properties of brain endothelial cells by platelet-derived sphingosine-1phosphate. J Cereb Blood Flow Metab 2005;25:1171-1182.

34. Andrews RK, Berndt MC. Snake venom modulators of platelet adhesion receptors and their ligands. Toxicon 2000;38:775-791.

35. Marcinkiewicz C, Lobb RR, Marcinkiewicz MM, et al. Isolation and characterization of EMS16, a C-lectin type protein from Echis multisquamatus venom, a potent and selective inhibitor of the $\alpha 2 \beta 1$ integrin. Biochemistry 2000;39:9859-9867.

36. Saegusa J, Akakura N, Wu CY, et al. Pro-inflammatory secretory phospholipase A2 type IIA binds to integrins $\alpha \mathrm{v} \beta 3$ and $\alpha 4 \beta 1$ and induces proliferation of monocytic cells in an integrin-dependent manner. J Biol Chem 2008;283:26107-26115.

37. Brooks PC, Stromblad S, Klemke R, et al. Antiintegrin $\alpha v \beta 3$ blocks human breast cancer growth and angiogenesis in human skin. J Clin Invest 1995;96:1815-1822.

38. Francis SE, Goh KL, Hodivala-Dilke K, et al. Central roles of $\alpha 5 \beta 51$ integrin and fibronectin in vascular development in mouse embryos and embryoid bodies. Arterioscler Thromb Vasc Biol 2002;22:927-933.

39. Milner R, Campbell IL. Developmental regulation of $\beta 1$ integrins during angiogenesis in the central nervous system. Mol Cell Neurosci 2002;20:616-626.

40. Yamazaki Y, Matsunaga $Y$, Nakano $Y$, et al. Identification of vascular endothelial growth factor receptor-binding protein in the venom of Eastern cottonmouth. A new role of snake venom myotoxic Lys49phospholipase A2. J Biol Chem 2005;280:29989-29992.

41. Fujisawa D, Yamazaki $Y$, Lomonte $B$, et al. Catalytically inactive phospholipase A2 homologue binds to vascular endothelial growth factor receptor-2 via a C-terminal loop region. Biochem J 2008;411:515-522. 